


\section{VOLUME EIGHT, NUMBER ONE, 2010 ISSN: 1596-9231}

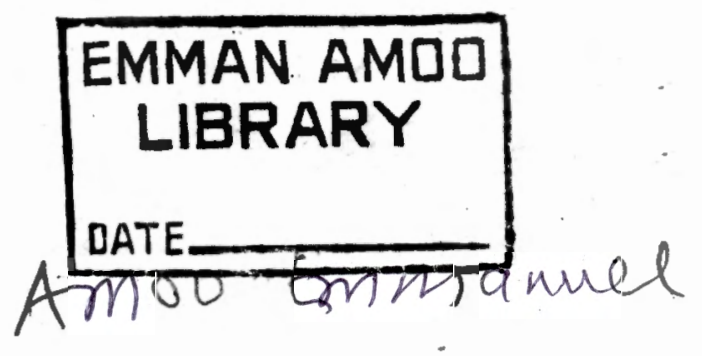

Published by the Ife Centre for Psychological Studies, Ile-Ife, Nigeria. 


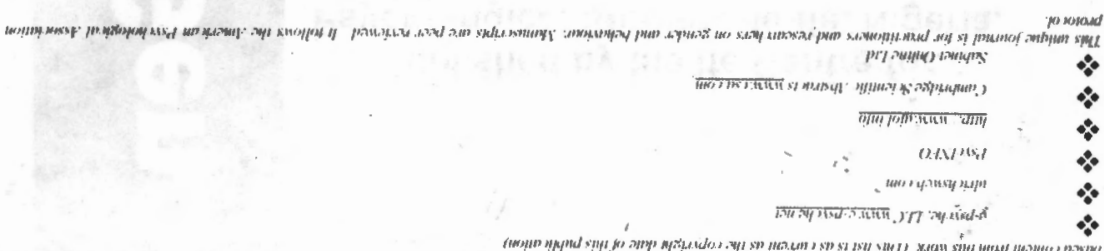

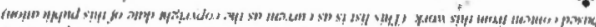

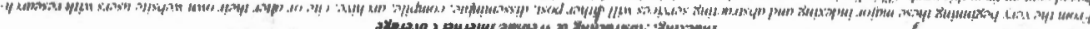

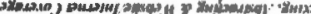

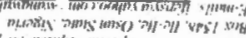

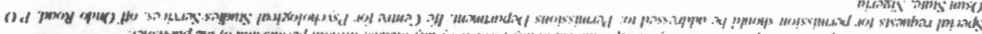

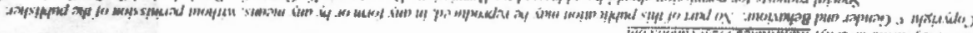

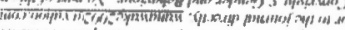

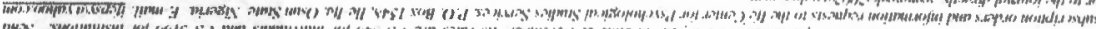

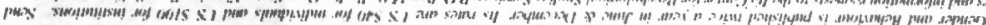

\section{NOILIIYOANI SУสgI8.JSG.IS .}

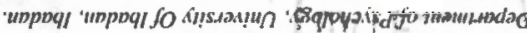

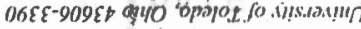

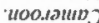

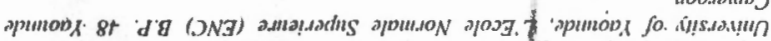

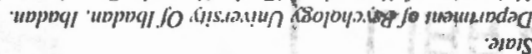

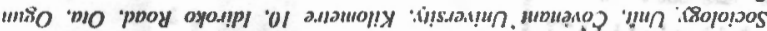

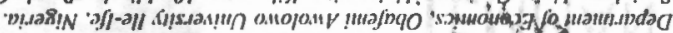

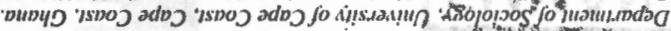

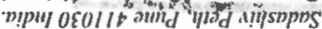

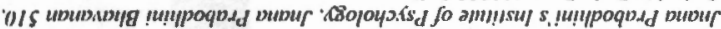

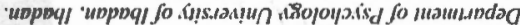

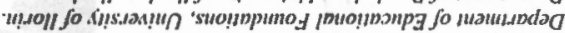
omis ums

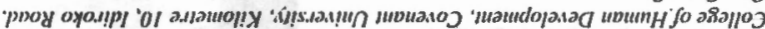

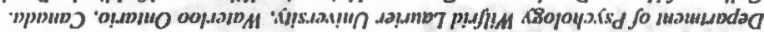

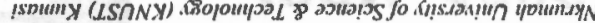

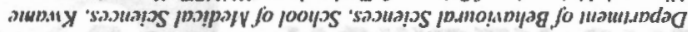

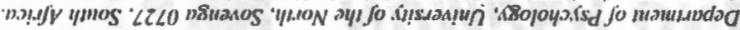

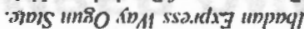

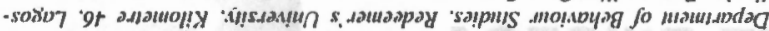

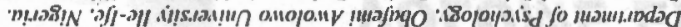

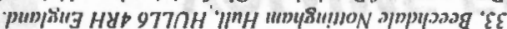

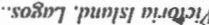

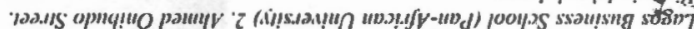

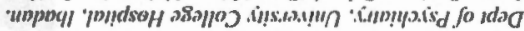

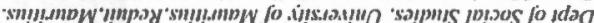

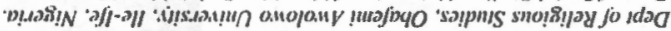
mum 'b.s.J.

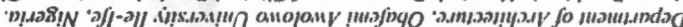

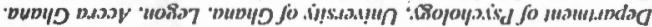

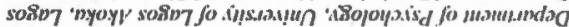

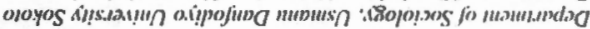

'p!..

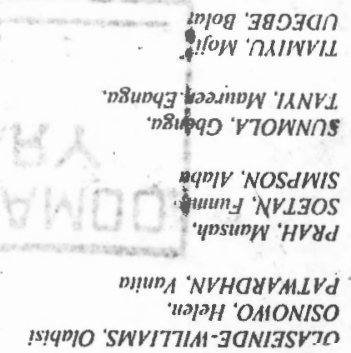

$7 V$ "NVRGO "sulydasor 'OOGIVN

"vumug $H V S N 3 W$ iN sompls navlv

H!. 10IMMMO \%VNVS37I

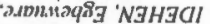
'mp!qnoZ 'VNINYGกD

'PMUDY) ' $3 / d 3$

DoS "VOกNVMกTO NIVAHdJ "MII ${ }^{\circ}$ NOAIOHG ! (1)7og 3 $3 \times 3.4 V 9$

'भD"!G WOOAO-HVVG odroog '37OWV :4!..MIS VILOYV

'очm!ч! " 'mu!nd nWVaV SHOLIOII

mosumy n.11070

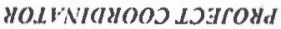


Amo Emmanuel

08035520849

Jemography $\alpha$ for statistes

Corenant unwersid
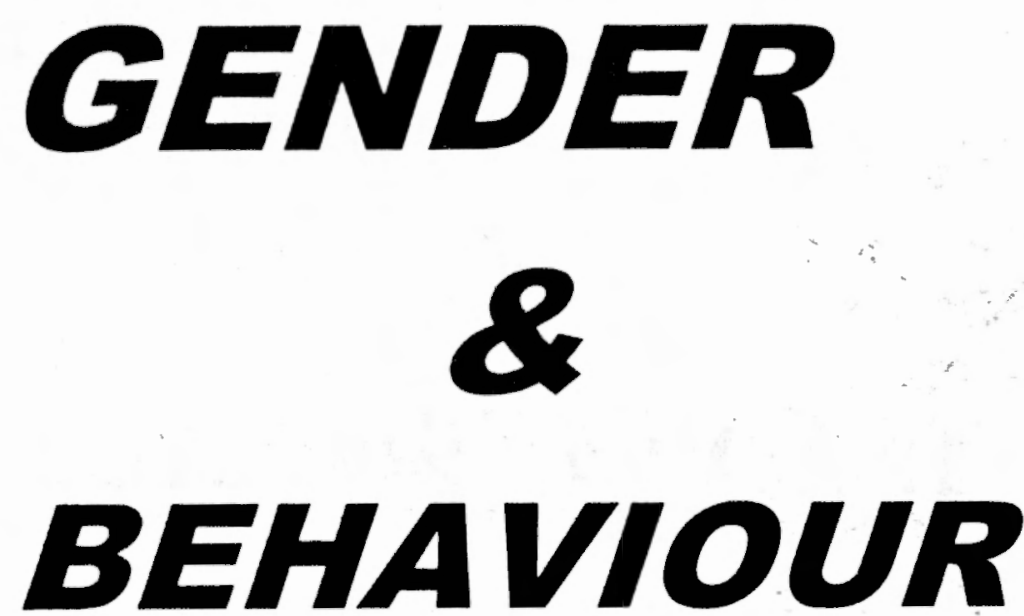

Volume 8 No 1, JUNE, 2010

Published by:Ife PsychologIA (RC 011934)

Ife Centre for Psychological Studies/Services.

P.O. Box 1548, Ile-Ife

Osun State, Nigeria.

$\&$

The Network of Psychological Studies of Women Issues

Department of Psychology

University of Ibadan

Ibadan. 


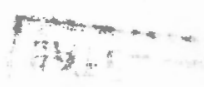

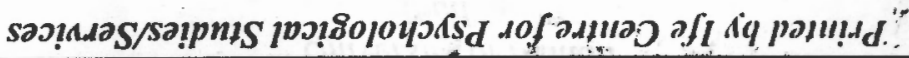

\section{IEZ6-96SI :NSSI}




\section{EDITORIAL}

We have continued our battle against the following; symbolic annihilation of women by the media, unequal opportunities throughout the education system, the sexual division of labour and sexist ideology of the workplace. We positively support the sanctioning of violence against women and the commoditization of female sexuality.

From the work of Chiloane-Tsoka and Wilma Mayhew to that of Dr. Kehinde Ayenibiowo we have documented how, ráce, culture and social class inequality may make the effects of gender intequality worse for some groups of women. Genuine equality is unlikély until men are willing to join women in directly changing the political, economic and ideological structures in society that have traditionally accorded them greater power and priviledges. This requires more than simply an increased awareness of and sensitivity to women's concerns. It means using one's priviledged position to pressure sexist institutions into redistributing goods and services, and ultimately, it requires the relinquishing of some power and priviledge to women themselves. This redistribution of power and other resources must occur in the family as well as in more public institutions.

We believe that the twenty-five articles in this Volume Eight Number One, 2010 of our joumal will go a long way at pursuing our mandate to a great extent. As usual, we are grateful for your support. God bless.

\section{Sincerely yours,}

Professor A.A. Olowu; Ph.D; F.C.I.P.M

Project Coordinator; Gender \& Behaviour

Ife Centre for Psychological Studies/Services

P.O. Box 1548, lle-Ife,

Osun State, Nigeria.

Phones: $08037116382 ; 08056343255$

Email: ifepsyri yahoo.com

Web: www.ifepsychologia.org

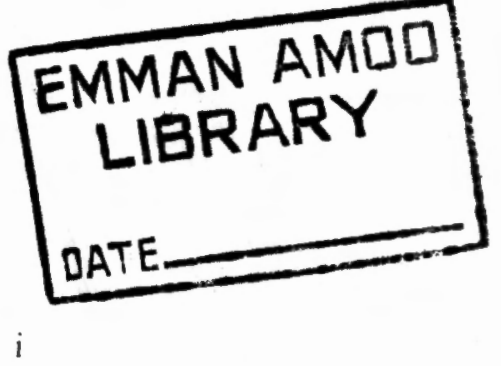


"Sure God created man before woman. But then you always make a rough draft before the final masterpiece"

Author Unknown 


\section{Volume Eight}

Number One

\section{CONTENTS June, 2010}

NAME OF AUTHORS

EDITORIAL

CONTENTS

GE CHILOANE \&

IVILMA MAYHEW

IRUONAGBE, T.C.

KARL PELTZER

LAIVAL, A.O

EPIE, C.E i

iii

2590 Difficulties Encountered by Black Women Entrepreneurs in Accessing Training from the Small Enterprise

Development Agency in South Africa.

2603 Women's Land Right and the Challenge of Patriarchy: Lessons from Ożalla Community, Edo State, Nigeria.

2618 Chronic Diseases Risk Factors and Access to Health Exams among Women in South Africa.

2629 Brcastfeeding and Emotions of Infants of Working Mothers in Adekunle Ajasin University Akungba-Akoko.

2638 Gender, Religiosity and Self-Esteem as - Predictors of Sexual Attitudés of Students in a Nigerian Tertiary Institution.

2649 Benefits of Family-Responsible Management in the Nigerian Environment - A comparison of Two Breweries.

2666 Gender Factors affecting Femalc Labour Input in the Nigerian University System. 
NAME OF AUTHORS

KOYLNIKAN, M.J.

RE.MI AKUJOB!

ADEYIIYE, M.M \&

AKINBAMI, C.A.O

()KI.I)I.JI, A.A, NI)(O.M, А.S

de. $A F() ! A B, O . A$

AIERINTO, A.A

GIROH, D.)', IGIBINOSA,

F.O \& UMAR, H.Y

NRASOLA, F.F

FASHINA, F.F \&

MATIIILIV, A.O

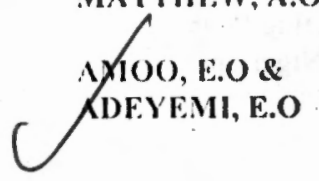

\section{TITLE OF ARTICLES}

2677 Gender Analysis of Participatory Needs Assessment of Emeroke Comnunity of Akwa Ibon State, Implications for Agricultural Extension Interventions.

2690 Signifying "Otherness" and the Politics of Exclusion: Effects of Stignatization on the Psyche of Female Lepers and Beggars in Nigeria.

2703 Women and Gender Budgeting: Nigeria's Policy Alternative

2724 Effects of Incentive and Gender on - Computer Skill Acquisition.

2735 Sexual Abuse of the Girl-Child in Urban Nigeria and Inplications for the Transmission of HIV/AIDS.

2762 Analysis of the Contribution of Women in the Production of Hevea Planting Materials and Latex in the Rubber Belt of Nigeria.

2771 Correlation between Parenting Styles and Sexual Attitudes of Young People in Nigeria: Comparison of Two Ethnic Groups.

2789 Religion, Gender and Development: Emerging Issues.

2805

Scanty Dressing Habit and Sexual Comportment among Adolescent Girls in Metropolitan Lagos:

Implications for the Transmission of HIV/AIDS. 


\section{NAME OF AUTHORS}

IIITSS IINI, II.)

PliLI\%ER, K., II/OL.O. T..

MIBIII.L.. N., ISSOMI, l..,

LKWA, N NCITARALO, N.

INIIIONDF, II.O... II)IAKHEUA, 2846

K.(O.. O' EN.ANIBIORSHIORA,

().1:

OYEBBANJI, G.O. S SUPA I'LN(IPI)

M.IDU, S.N., ND().I, J.E \&

RIMIASHII, C.L.

MIII) I, B.IR

KOH.IJIINSON

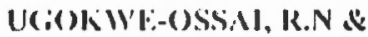

UCIILACIIIU, V.A

MIENIBIOWO, K.()
2825 Economic Empowerment of

Nigerian Women through Proper

Application of Loans and Management of Capital.

TITLE OF ARTICLES

2833 Dual Protection, Contraceptive Usc HIV Status and Risk among a National Sample of South African Wonsen.

Quality of Life amòng Fennale Workers in Edo State: Consicleration of Job-Type Age and Marital Status.

2857 Knowledge, Attitudes and Practice of Family Planning following Tcrnination of Pregnancy among Basotho Women at Queen Elizabeth II Hospital, Maseru, Lesotho.

2871 Depression among female Survivors of Domestic Violence in Thohoyandou, South Africa.

2886 Perceived Socictal Expectations of Boys and Girls on the Learning of English as Second Language and how they affect their Performance.

2903 Sexual Harassment in the Workplace A case Study of Nigeria.

2919 Eflects of Gender and Recall Types on Memory Loops of Working Memories in Elderlies.

2930 Culture and Giender as Predictors of Undergraduates' Perception of Gender Roles. 


\section{NAME OF AUTHORS}

Abstracting \& Indexing

PsycINFO Journal

Ulrich International Directory

Reach Us

Sabinet Online

Invitation to Subscribe

Communication with the Editors

Ife Psychologia (RC LAZO 11934)

Ife Psychologia

African Journals Online
TITLE OF ARTICLES

2948

2949

2950

2951

2952

2953

2954

2955

2956

2957 


\title{
SCANTY DRESSING HABIT AND SEXUAL COMPORTMENT AMONG ADOLESCENT GIRLS IN METROPOLITAN LAGOS: IMPLICATIONS FOR HIV/AIDS INCIDENCE
}

\author{
AMOO Emmanuel Olagunju* \\ College of Development Studies, Covenant University, \\ Ogun State, Nigeria \\ 8 \\ ADEYEMI, Ezekiel Olugbenga (PhD) \\ Department of Sociology, Faculty of Social Sciences, Lagos State. \\ University, Ojo Lagos. Nigeria \\ The sanctity of proper dressing in sub-Saharan \\ Africa was always adhered to few years back, not \\ until recently when relaxation on dressing habit \\ crept in and is now completely being overturned and \\ conspicuously replaced by obscene habit of half \\ nakedness and nudity. The study examined the \\ effects of the acquiescent of Nigerian society \\ towards the preponderance of scanty dressing, \\ pornography (and the like) on adolescents' sexual \\ behavior and its probable effects on the incidence of \\ HIV/AIDS. 283 adolescents in age group 10-19 \\ years were interviewed in Lagos State of Nigeria. \\ The study revealed that there is a negative \\ relationship between girls' dressing habit and level \\ of sexual comportment. It revealed that those that \\ are scantily dressed are vulnerable to sexual acts \\ and are likely to be more exposed to HIV/AIDS than \\ otherwise. 73.1percent of respondents considered \\ communication on sexuality with their parents as \\ very poor. About 88.3 percent respondents wear \\ "see-through", transparent trouser/pants, "hips \\ stands" dresses outside their homestead and the \\ motives range from "want to be noticed by big \\ boys", "dress to thrill" to "sex for cash". 62.2 \\ percent have experienced sexual intercourse and \\ $51.9 \%$ out of this magnitude have had it within the:
}

* Mobile phone/snail: +234 8035520849 /emman amoo2007@ayahoo.com 
last three month of the survey. Two-third do not use condom during intercourse while several do not have stable sexual partners. Indulgence in scanty dressing could be curtailed by the provision of adequate sexuality education and respect for Nigerian value of dressing. Responsible sexual comportment is possible by embracing modest dressing lifestyles among others.

Key Words: Scanty dressing, adolescent, aristo, HIV/AIDS, STDs, sexuality, nudity, girl-boy friend.

\section{Introduction}

Until recently, Nigerians honoured the sanctity of proper dressing habit. However, the advent of relaxation on dressing especially among young girls in sub-Saharan Africa and Nigeria in particular has threatened the cultural personality of the average Nigerian women. Since proper dressing was regarded as part of normal sociocultural standard that required no authority to enforce compliance. Every one grew up to embrace proper dressing as a way of life. In today's world, the event has been overturned and conspicuously replaced by obscene habits of half-nakedness and nudity (Odeleye, 2000; Rubinstein, 1995; Kuruvilla, 2007; Ojo and Odeleye, 2008.) while the phenomenon would have been regarded as mere advent of new culture or cultural diffusion from the western world, its display in both public and 'reserved places' calls for serious concern. In addition, the fact that the young adolescent girls are the most vulnerable to this cultural pollution makes the trend a worrisome development. Apriori expectations were that scanty dressing habit could have some effects on the sexual behaviour of adolescent girls which make them to be more exposed to HIV/AIDS. This, in all ramifications, might not augur well for the future development of this country and other nations of sub-Saharan Africa. It is believed that nudity imitation is damaging missile into the lives of the adolescent girls. It sends positive signals to men who might sexually victimize them. This portends danger to already appalling level of sexual abuses that this category of girls faces in contemporary society.

Scanty dressing behaviour is an embodiment of anti-social comportment that is entrenched by the fad. It is a social change that is at variance with modest dressing habit which could attract other vices especially when considering the caliber of superficially 
mature adolescent girls who could take this liberty for license and explore its negative aspects for sexual gratifications. Scantily dressing could be misinterpreted by delinquent members of the opposite sex as an invitation for sexual congress. Therefore if all laudable objectives and efforts towards elimination/reduction of HIV/AIDS as visibly enshrined in Millennium Development Goals, National reproductive health strategic framework and plan (Federal ministry of Health, FMOH, 2002), HIV/AIDS prevention guidance for reproductive health (Population Council and UNFPA, 2002), population and the quality of life in Nigeria (National Population Commission (NPC) and FMOH, 2004 and Vision 2020 are to yield fruitful results, all avenues to sexual immorality among this most vulnerable group should be discouraged. Thus, it is apparent that there is need to urgently scout out the illicit motives behind this new development in dressing habit. This study targeted the adolescent girls because of the position they occupy in continuity of life and sustainable development of every nation.

Specifically, adolescent is a period which an individual makes a gradual transition from childhood to adulthood. It is a period of being working towards independent from family members and establishing oneself among peers. An adolescent naturally become aware of their sexual drive and feels to be handled, touched, loved. and cared for by someone of the opposite sex in the face of erroneous belief that she is 'matured' and can take meaningful decisions on her own but without adequate knowledge of future implications (Faoye and Lana, 1998). They are beset with myriads of challenges such as unwanted pregnancy, induced and unsafe abortion, sexually transmitted diseases including HIV/AIDS, contraceptives use, childbearing, early marriages and so on. Therefore it is believed that this group of people required true knowledge of certain facts of life and informative literature that will guide them towards responsible and safe sexuality, hence the need for this study.

The thrust of this study among others is to examine the emerging permissiveness of scanty dressing habit in our society today and its effects on adolescent sexual comportments with their attendant implications for STDs/HIV/AIDS incidence in southwestern Nigeria. Effort was made to achieve this by finding out, amongst others, the perception of parents on scanty dressing habit and investigating the (hidden) motives behind certain dressing habits amongst adolescent girls (aged 10-19 years). The study was also designed to examine the general community attitude towards scanty dressing habit as well as 
nudity. Socio-economic correlates of desire to be nude and wearing of revealing clothes were identified. The two hypotheses formulated were: whether there is a significant relationship between socioeconomic status, education, religious commitment, occupational status and scanty dressing habit; and whether there is a significant relationship between scanty dressing habit and incidence of sexual abuses and probable exposure to STDs/HIV/AIDS infections.

Among the important contributions of the study is that it revealed that education, sexuality education, awareness about HIV/AIDS are significantly negatively related to the scanty dressing habit. This therefore serves as a signal to researchers, stakeholders and governments regarding all interventions towards the menace of HIV/AIDS in Nigeria and other developing nations. In addition, the study is to fill the gap of dearth of information on interconnections between scanty dressing habit and probable exposure to HIV/AIDS infections.

\section{Literature review}

The world has become a global village with high preponderance of iriter and intra cultural transference of which dressing culture is not an exemption (Ojo and Fasubaa, 2005). However, while the dressing of a woman should show modesty and respect especially in the modern society of today, the presence of different kinds of tight transparent fashions, half dressing styles and nudity could be regarded as dishonour to the female folk (Wardrobe, 2006; Matthew, 2007). It is also a fact that variety of fashion are evolving from our ancestor's ancient mode of dressing to the current designers' dresses and suits over the years, but as society becomes trendy there is also a danger of failing to distinguish between what is fashion and what constitute's indecent dressing. With or without clarification, it is important that whatever has positive connotation with HIV/AIDS incidence should be avoided. Thus, there is the need for adequate understanding of the likely interconnections between dressing nature and sexual behaviour especially among the tender group who are by nature the opium of future development.

On the other hand, the alarming rate of cases of young girls who are being harassed by call-boys for being cladding carelessly seems to suggest that the proper definition of fashion in this age seems to have been misunderstood (Mangani, 2005). Adolescents are more predisposed to sexual activities nowadays because of some changes 
that have taken place in social system in the countries including Nigeria (Onwuamanam, 1995). While no one is contesting that women are free to exercise their human rights by dressing the way they wish in the name of fashion, the opposite sex could feel provoked by the offensive dressing displayed by the womenfolk (Mangani, 2005). It is no gainsaying that individual differences exist in wardrobe selection, and the fact that there are virtually no rules in terms of fashion especially in Nigeria, dressing etiquette is assumed to be understood by majority. Thus, concern is always raised wherever and whenever, this generational rule of thumb is flouted. The phenomenon aggravates more anxiety if those involved are the young folks who by nature gravitate to adults of tomorrow that could be economically harnessed for progressive development of our nations.

Study in adolescent sexuality is not new especially in the part of the country where this study was conducted. Among several authors that have dealt on various issues of sexual networking, multiple partners and HIV/AIDS include but not limited to the following: Caldwell and Quiggins (1989), Caldwell and Caldwell (1996), Owumanam (1995), Augustina (2003) and Action Health.Incorporate (2007). The fact that demographic events are dynamic in nature, and of course, for the basic reason that various unprecedented demographic patterns and changes in the world today have distorted or affected most handed-down standard definitions of population compositions validates the importance of continuous study on population phenomena (Caroline and Barney, 1993). This study is another eyes opener in the area of dressing and its linkage with sexual behaviour and HIV/AIDS incidence among the adolescents. Adolescent girls as implied in this context mean girls in ages between 10 and 19 inclusive. Adolescent is a period of intense sexual drive, sexual experimentation and exploration, thus the new dispensation of sexual behaviour as exemplified by the scanty dressing habit requires thorough investigation. Although, various definitions abound for this group of population, the World Health Organisation (WHO) refers to adolescence as a period of transition from childhood to adulthood characterised by individual entry into puberty (WHO, 1989). It is an embodiment of a rapid change in biological, psychological and socio-cultural aspects of life and an upward progression socio-economic dependence to relative independence (WHO, 1989; WHO, 1999; Population Reports, 1995; Augustina, 2003; Federal Ministry of Health, 2007). 
For the purpose of this study, scanty dressings connote the wearing of wears/dresses that are barely sufficiently covering the body. A scanty dress only covers the body from the waist no further than to the thighs or not adequately covering the waist. They are significantly less clothing than expected by the conventions of our culture and situations. Scanty dressing habit therefore represents the cladding in low cut clothes that do not cover the interest arousing parts and intimate parts of the body. It exposes girls' panties, sensitive parts of the body, bare back exposure, body contours, belly buttons, plain stomach exposure, bare skin, etc. These dresses are so insufficient that they obviously offend moral sensitivities of decent members of society.

HIV/AIDS is a ravaging disease and sub-Saharan Africa region has been the hardest-hit by it. Its pattern in the region is acclaimed to be unique and the male-female dichotomy puts female at disadvantage than the converse. Over 6000 young people are contacting HIV daily and in sub-Saharan African region and 62 percent of the people living with HIV/AIDS are young women (Population Council and United Nations Population Fund (UNFPA), 2002; UNAIDS, 2002; National Population Commission (NPC) and Federal Ministry of Health (FMOH), 2004). In addition, heterosexual intercourse is the most potent medium of its transmission in the region compared to other forms in other areas across the globe (Marc et al, 2003; Pemplenani, 2003). Notwithstanding that it was first discovered about 24 years ago in Nigeria, the prevalence rate which was 1.8 percent in 1991, rose to 3.8 percent in the 1993, 4.5 percent in 1995 and. average of 5.2 percent in the year 2007 (Federal Ministry of Health (FMOH), 2007). Currently the prevalence rate in Nigeria is $4.4 \%$ distributed into 4.6 Urban and 3.9 rural areas (FMOH, 2005 and 2007). Till date, there is general yearning for a decline in incidence of this terminal disease in all nooks and crannies of the nation. Since its first discovery in Nigeria in 1986 and until 1991 there was no intervention assessment by the Nigerian government. Several campaigns, initiatives and other interventions have been on the increase but the disease is till with us today.

Adolescent in Nigeria constitutes 22 percent $(31,035,369)$ of the total population $(140,461,790)$ out of which 48 percent are adolescent girls (National population Commission NPC, 2010). Therefore, considering this magnitude and coupled with the fact that the risk of 
and the vulnerability to HIV infection is particularly striking among them, their sexual comportment should be of utmost importance. Beside, the country, like other nations within sub-Sahara Africa, is long been noted for recognition of polygamous, concubinage, mistress and outside wives (Caldwell, Caldwell, and Quiggins, 1989; Odebiyi and Vivekananda, 1991). This syndrome in the recent past has also transformed to boy-girlfriend relationship and sexual relationship between the adult male and young girls (popularly called "aristo" syndromel.

While several literature abound on sexual relationships, poverty as a push factor to prostitution or harlotry, researchers have failed to consider the seemingly factors that attract men to these younger girls looking at the age differences and their backgrounds." Dressing attracts and absolute indecent scanty dressing attracts sexually. The first index of attraction cannot be dissociated from dressing styles or appearance. Thus, analysis of adolescents' sexual behaviour cannot be completed without highlighting the interconnections between their dressing habits and their sexual life, hençe the need for this study.

\section{Research Design}

Quantitative and qualitative research approaches werè employed independently and complementally for data gathering. In the quantitative method, the survey data were collected through a faceto-face interview conducted by the author and four other trained interviewers. The study population consists of 283 adolescent girls who fall within the ages of 10 and 19 years in metropolitan city of Lagos in Nigeria. Although, the questionnaire was designed in English, every interviewer speaks and understands the universal adopted 'pidgin' language in the city and where necessary it was used to interpret the questions. In every case, a good rapport was established with the subjects and they were assured of confidential treatment of whatever information they supply. Already, each state has 20 Local Government Areas (LGAs) with each LGA sub-divided into constituencies which serves as umbrella for several wards with each housing a number of Enumeration Areas (EAs). These enumeration areas within the wards were strictly followed in selecting qualified respondents for the interview. Only two LGAs and two constituencies were selected from the state. In each of the constituencies, two enumeration areas (EAs) were selected. From each enumeration areas, 75 houses were randomly selected from number of houses in the street. One household was selected from a 
house/building and within the household only one female adolescent between the age of 10 and 19 years was interviewed. In all, 283 face-to-face interviews were successfully completed in the EAs selected for the study. Although this system followed a systematic sampling technique, the choice of the study areas was very subjective.

In the qualitative segment, focus group discussion (FGDs) and Indepth interviews were respectively used to enrich the result from the quantitative study. A total of four FGDs were organized amongst the target group while in-depth interviews focused only the parents and few stakeholders like the school proprietors and company directors.

Data analyses were a combination of three statistical analytical techniques namely: univariate, bivariate and multivariate analysis. The univariate segment comprises of descriptive statistics such as frequencies, to assess the socio-demographic characteristics of the respondents $s_{i}$. inter-dependent association amongst identified variables vis-a-vis indulgence in scanty dressing habit. Series of cross-tabulations were performed in the bivariate analysis to identify thê patterns of relationship between selected background variables and scanty dressing habit. Regression analysis was also employed as the third level of analysis principally to test hypotheses formulated. It was adopted because it can provide the line of best fit which explains how the typical value of the dependent variable changes when any one of the independent variables is varied assuming other independent variables are held constant (Hughes and Grawoig 1971; Sykes, 1993).

Information from the focus group discussions and in-depth interviews were transcribed and organized under different headings that depict different aspects of the discussion and used in explaining the quantitative analysis where and when necessary.

\section{Results and Discussions}

The demographic characteristics (table 1) indicated that the average age group of adolescents interviewed is 15-19 years. While 12.7 percent have not attended school, 60.4 percent had attained primary and secondary education while about 27 percent had experienced post secondary and other tertiary education. The parental status indicated that more than half of the respondents ( 58.3 percent) have 
both parents living and are staying together. Respondents from separated, divorced and single parent are $17 \%, 6.4 \%$ and $18.4 \%$ respectively. The child-parent rapport evaluated on a three point rating scale (very close rapport, little rapport, no rapport at all) show that 24.0 percent of the respondents have very close rapport with their parents, 40.3 percent described the rapport as very little while 25.7 percent claimed they have no rapport with their parents at all. In addition, the frequency of discussion with parents among those that have rapport with parents varied from very poor (41.3 percent), poor (31.8 percent), fair (11.3 percent) to good (15.5 percent) None of

\section{Table 1: Percentage distribution of respondents by selected socio-demographic variables, attitude toward scanty dressing habit and HIV/AIDS awareness}

\begin{tabular}{|c|c|c|c|c|c|}
\hline Variable & Freq & $\%$ & Variable & Freq" & $\%$ \\
\hline Age group & No & $\%$ & Prefer dressing style & & \\
\hline 10-14 years old & 111 & 39.2 & $\begin{array}{l}\text { See-through/ Hip stands/Body } \\
\text { hugs }\end{array}$ & 40 & 14.1 \\
\hline $15-19$ years old & 172 & $6 \overline{0.8}$ & Scanty/Skimpy & 105 & 37.1 \\
\hline Education Attainment & & & Sleeveless /Strapless & 39 & 13.8 \\
\hline No Schooling & 36 & 12.7 & Transparent/pant revealing & 66 & 23.3 \\
\hline Primary Education & 75 & 26.5 & None & 33 & 11.7 \\
\hline 2ndary Education & 96 & 33.9 & Skimpy/scanty Wearing & & \\
\hline Post secondary / Tertiary & 76 & 26.9 & Very often & 89 & 31.4 \\
\hline Living status of parents & & & Often & 122 & 43.1 \\
\hline Both living together & 165 & 58.3 & Not often & 33 & 11.7 \\
\hline Separated & 48 & 17.0 & Not at all & .39 & 13.8 \\
\hline Divorced & 18 & 6.4 & $\begin{array}{l}\text { Opinion about scanty } \\
\text { dressing }\end{array}$ & $\cdots$ & \\
\hline Single & 52 & 18.4 & Decent & 192 & 67.8 \\
\hline $\begin{array}{l}\text { Parent-Child Rapport's } \\
\text { Level }\end{array}$ & & & Indecent & 50 & 17.7 \\
\hline Very close Rapport & 68 & 24.0 & Indifferent & 41 & 14.5 \\
\hline Little Rapport & 114 & 40.3 & $\begin{array}{l}\text { Ever Heard Lecture on } \\
\text { Dressing Code }\end{array}$ & & \\
\hline No Rapport at all & 101 & 25.7 & Yes & 160 & 56.5 \\
\hline \multicolumn{3}{|c|}{$\begin{array}{l}\text { Discussion of dressing habit/sexuality } \\
\text { with parents }\end{array}$} & No & 123 & 43.5 \\
\hline Very Poor & 117 & 41.3 & Harassment & & \\
\hline Poor & 90 & 31.8 & Physical Harassment & 98 & 34.6 \\
\hline Fair & 32 & 11.3 & Unwanted touched & 82 & 29.0 \\
\hline \multirow[t]{2}{*}{ Good } & 44 & 15.5 & Verbally molested & 59 & 20.8 \\
\hline & & & Not at all & 44 & 15.5 \\
\hline \multicolumn{6}{|c|}{ Attitude toward dressing habit and HIV/AIDS awareness } \\
\hline $\begin{array}{l}\text { Feeling when wearing } \\
\text { scanty dress }\end{array}$ & & & $\begin{array}{l}\text { Ever experienced sexual } \\
\text { intercourse }\end{array}$ & & \\
\hline Very attractive & 125 & 44.2 & Yes & 176 & 62.2 \\
\hline Attractive & 134 & 47.3 & No & 107 & 37.8 \\
\hline Unattractive & 24 & 8.5 & Had sex in the past 3 months & & \\
\hline $\begin{array}{l}\text { Wear to get attracted } \\
\text { only }\end{array}$ & & & Yes & 147 & 51.9 \\
\hline Yes -1 & 120 & 42.4 & No & 29 & 10.2 \\
\hline No & 163 & 57.6 & Not Applicable & 107 & 37.8 \\
\hline
\end{tabular}




\begin{tabular}{|l|c|c|l|c|c|}
\hline $\begin{array}{l}\text { Freq of men attempting } \\
\text { to woo you }\end{array}$ & & $\begin{array}{l}\text { Information ever heard on } \\
\text { HIV/AlDS Prevention }\end{array}$ & & \\
\hline Very frequent & 125 & 44.2 & Avoid casual sex & 29 & 18.13 \\
\hline Frequent & 134 & 47.3 & Limiting to one sexual partner & 14 & 8.75 \\
\hline Not at all & 24 & 8.5 & Sinful & 117 & 73.13 \\
\hline Awareness of HIV-AIDS & & & $\begin{array}{l}\text { Use Condom against } \\
\text { HIV/AIDS }\end{array}$ & & \\
\hline Yes & 149 & 52.7 & Use condom & 37 & 13.07 \\
\hline No & 134 & 47.3 & No & 139 & 49.12 \\
\hline Total Respondents & $\mathbf{2 8 3}$ & $\begin{array}{c}\mathbf{1 0 0} \\
\mathbf{0}\end{array}$ & $\begin{array}{l}\text { Not Applicable } \\
\text { Total Respondents }\end{array}$ & $\mathbf{2 8 3}$ & $\begin{array}{c}\mathbf{1 0 0} \\
\mathbf{0}\end{array}$ \\
\hline
\end{tabular}

Source: Field Survey 2009

the respondent rated the level of discussion on sexuality with her parent as very good (table 1). Amongst various reasons adduced for this are: "the nature of work of their parents", "their non-availability at horne or non-disposable for discussion". Others include, "not the family practice" and "never considered it as an issue worth discussing". This revelation indicated a great vacuum and laxity in parental obligations especially in discussion of dressing habit and behavior of the adolescent in the study areas.

Questions were canvassed on several dressing styles that respondents wear regularly and the response (table 1) shows that 37.1 percent wear scanty and skimpy styles, 23.3 percent prefer transparent/revealing drésses, 14.1 percent wear see-through, 13.8 perçent are used to sleeveless/strapless and about 12 percent are not addicted to any style. Majority of adolescents considered scanty dressing styles as 'normal styles' and could not perceived any danger in wearing it to any occasion, anytime and at anywhere. Majority of the respondents regarded scanty dressing habit as pleasant and appropriate styles for their age while the minority considered that it could have some endangering effects on the dignity of womanhood. More than two-third wear these dress regularly (Table 1).

The study confirmed that about 56.5 percent of respondents have heard lectures/instructions on types of dresses for outside home, 43.5 per cent have never been privilege to have such. Out of 160 respondents that have received lectures on dressing habit and sexuality, majority claimed that the social invectives of scanty clothing/dressing were not mentioned. The major reason why they prefer scanty attire and responses rarige from "want to be noticed by big boys"; "dress to thrill" to "sex for cash". 
The levels of consensual and non-consensual sexual attractions examined and the finding shows that nearly all that indulge in scanty dressing (91.35 percent) enjoys frequent wooing from their male acquaintances than their other counterparts. Table 1 also revealed that most scantily dressed girls have experienced physical harassment (34.6\%), unwanted touching $(29 \%)$ and verbal molestation $(20.8 \%)$ from their male counterparts on different occasions. While among those that have experienced sexual intercourse, 51.9 percent have had casual sex at least once in the past three months, it is revealing to note that two-third of this category of respondents did no use condom during intercourse. Higher proportion of these girls claimed that they do not have stable sexual partners while over 50 percent of the respondents claimed that their partners are also having other partners.

The acquiescence of the Nigerian society towards the preponderance of scanty dressing is pungent and the concomitant adverse effects on adolescent girls' sexuality could be easily imagined especially in a globalised world of today. The study shows that there is a direct relationship between dressing habit and indecent sexual comportment. That positive relationship exists between girls that wear scanty attire and incidence. of unwanted sex, unwanted pregnancies, early marriages, sexual violence/rape and abortion. Out of about 67 percent of respondents that wear scanty attire, 72 percent get wooed for friendship/partnership on regularly basis and by different male friends or acquaintances. About 33 percent claimed they are satisfied with meeting new acquaintances on regular basis and would not want to stop wearing such attire or at least for now. About 67.8 percent (table 1) considered the habits as decent while several claimed it is 'what is in vogue' though they believed that they are not always feeling secure especially while walking along the street/road. While several respondents expressed that "fulfillment in participating in the latest wear is incomparable with whatever bully anyone might be receiving", others expressed that "it is the excessive consciousness you feel whenever you wear it that makes it more interesting to wear". The FGDs also revealed more as indicated hereunder:

"you will feel all the time that you are wearing someihing different from other",

"you will be well noticed" everyone around appraise you" "guys around are compelled to say hi", 
"People like pretence, everybody like it and they greet you or are forced to look at you if you wear such"

Respondents are generally aware of the possible causes of HIV/AIDS and that AIDs is a terminal disease notwithstanding that it can be managed. Nearly all respondents believe it is preventable. Despite this level of awareness, it is amazing that many of them do not consider themselves to be at risk. Majority believed that "HIV/AIDS is not the end of life" and the impression is that some of them are deliberately ignoring it. There is a desperate youthful yearning to be loved, admired and enticed by the opposite sex and they are getting positive response thereby daring the consequences of risky sexual behaviour.

Survey respondents were unmarried adolescents but about 62.2 percent of them have experienced sexual intercourse and 51.9 percent of this number had it within the past 3 months (table 1). Worse still, of those who have experienced sexual intercourse, only 37.8 percent used condom (table 1). This observation points to the fact that the precautionary measures being taken by them were not sufficient and incomparable with the risk rate. It is indicated in the group discussion that a scantily dressed girl has more chances of being wooed by passers-by or new male acquaintances. She possesses the tendency to succumb (i.e. agree to their proposal), especially if they were the 'big boys' who will be willing to "squander money" on them.

The consensual opinion of the respondents during the FGDs in the study locations was that the parental provisions in the area of finance were considered as insufficient by most adolescent girls, hence the need to get someone who could fend for them. Respondents said that the most potent way of achieving financial help is via "aristo" (i.e. older male who could spend money on the girls for fun or for sex). Majority considered the thought of alternative "economic activities to augment parental financial assistance as unfathomable since those jobs are very scarce in the country. Other purported reasons include; difficulty in securing admission to higher institutions, the mismanagement in the nation where only the rich are getting richer and the poor becoming poorer, high standard of living in the country and the drive to survive at all costs. However, about one-third of the survey population would like to take up any full, part-time or pther causal works if and whenever available. A view of the subjects is shared below: 
"How do you want us to survive when the whole world is not ready to help anybody?"

"AIDS is real, but should we die of hunger because of AIDS" "many people alleged of AIDS are not AIDS victims but victims of lack of food and poverty"

"Which is better, to be hungry without any comfort or to be infected (with AIDS) and secure sympathy" "you can't know how much you are worth until you try these styles"

"several people say hi babe, you look beautiful, nice, and the discussion continues"

The regression analysis (table 2) shows that amongst the variable of interest tested, there are negative associations between predictor variables like reception of advice/instruction/lecture on dressing habits, HIV/AIDS awareness, educational attainment and level of harassment experienced when putting on scanty clothing/dresses as indicated in table 2. However, respondents' level of education is not significantly related to scanty dressing habit $(\mathrm{P}=0.094)$.

\section{Table 2: Regression Analysis}

a All requested variables entered.

b Dependent Variable: Skimpy/scanty Wearing

\section{Model Summary}

\begin{tabular}{|l|l|r|r|r|}
\hline Model & $R$ & R Square & $\begin{array}{c}\text { Adjusted } R \\
\text { Square }\end{array}$ & $\begin{array}{c}\text { Std. Error of } \\
\text { the Estimate }\end{array}$ \\
\hline 1 & $.338(a)$ & .114 & .085 & .94677 \\
\hline
\end{tabular}

a Predictors: (Constant), Harassment, Age group, Living status of parents, Parent-Child Rapport's Level, Education Attainment, Ever Heard Lecture on Dressing Code, Awareness of HIV-AIDS, Verbally assaulted, Freq of men attempting to woo you

\section{ANOVA(b)}

\begin{tabular}{|ll|r|r|r|r|r|}
\hline \multicolumn{1}{|l|}{} & \multicolumn{1}{|c|}{$\begin{array}{c}\text { Sum of } \\
\text { Squares }\end{array}$} & \multicolumn{1}{c|}{ Df } & \multicolumn{1}{c|}{$\begin{array}{c}\text { Mean } \\
\text { Square }\end{array}$} & \multicolumn{1}{c|}{$\mathrm{F}$} & \multicolumn{1}{c|}{ Sig. } \\
\hline 1 & Regression & 31.580 & 9 & 3.509 & 3.915 & $.000(\mathrm{a})$ \\
& Residual & 244.710 & 273 & .896 & & \\
& Total & 276.290 & 282 & & & \\
\hline
\end{tabular}

a Predictors: (Constant), Harassment, Age group, Living status of parents, Parent-Child Rapport's Level, Education Attainment, Ever Heard Lecture on Dressing Code, Awareness of HIV-AIDS, Verbally 
assaulted, Freq of men attempting to woo you

b Dependent Variable: Skimpy/scanty Wearing

a Dependent Variable: Skimpy/scanty Wearing

\section{Coefficients(a)}

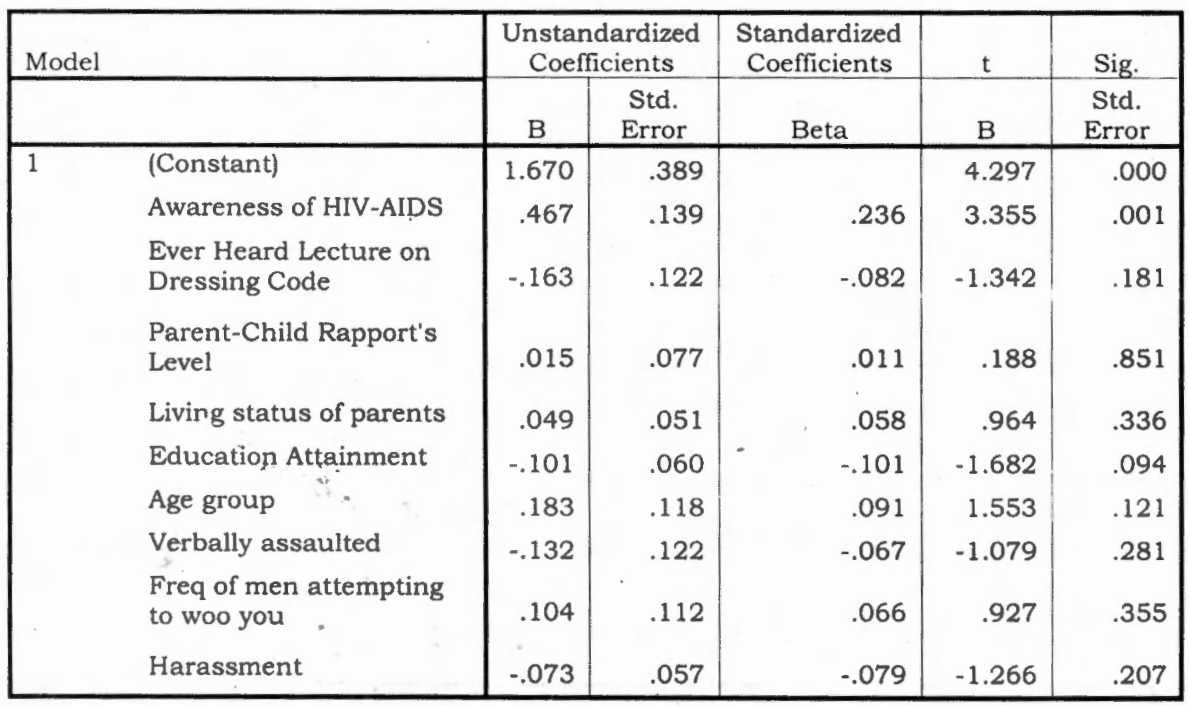

a Dependent Variable: Skimpy/scanty Wearing Source: Field Survey 2009

Although this implies that as the level of education increases among the adolescent girls, the likelihood of scanty dressing habit reduces but the relative-impact of education cannot be pungent except in conjunction with other variables. It is interesting to know that the awareness of HIV/AIDS is significantly negatively related to scanty dressing habit $(P=0.001)$. The direction of the relationship signals that it is an important factor that could be explored in stemming the habit of scanty dressing. As the awareness increases, its threat might compel modest sexual comportment which includes modest dressing habit. Therefore, researcher and stakeholders might have to integrate public enlightenment on interconnections between dressing habit and exposure to HIV/AIDS infections. A girl that dresses modestly might be accorded some level of respect and might escape being lured, wooed or exploited sexually thus limits her exposure to HIV infection. The analysis also revealed that 
instruction/advice/lecture on dressing habit is also negatively related to the habit of wearing scanty attire, though, the relationship is not significant $(\mathrm{P}=0.181)$ as indicated in table 2 . The prevailing poor sexuality education/instruction/advice (26.88 percent in table $1)$ is considered very low but significantly positively related $(p=0.001)$ to scanty dressing habit (table 2). This gives credence to the relevance of sexuality education from the child's ordained tutors (i.e. parents) and the community they live in. The more the restriction or clandestine handling of sexuality education especially at the home front, the more the habit would continue with its inherent dangers of exposing them to sexual misbeahvoiur.

\section{Policy Implications and Recommendations}

The study examined the emerging permissiveness of scanty dressing habit ámong adolescent girls, its effects on their sexual comportment and the ensuing plausible implications for HIV/AIDS incidence in metropolitan Lagos, Nigeria. It was observed that most parents permit the wearing of scanty dresses. Several institutions and establishments also feel unconcerned about what individual adolescent girl wears provided it does not hamper the profit or income earnings of such establishment. Overall, 74.5 percent of adolescent girls wear scanty dress among the 283 adolescent girls interviewed. This study is an eye opener to information on how social conditions of dressing affect reproductive health and transmission of STI including HIV/AIDS.

The result of the analysis has important implication for massive expenditure on HIV/AIDS awareness campaign. It is evident (from this study) that awareness of HIV/AIDS is no longer a major obstacle to the adolescent girls in the study areas but there is overwhelming lackadaisical attitude to risky sexual behaviour. There is a strong conviction that there exist some financial gains in sexual relationships especially with the call-guys (big guys). A unique contribution of the data is the enhancement of understanding of the interconnections between the 'men-pull-factors' in terms of sexual misdemeanour and the young adolescents girls. The outcome of this study indicates that the surging waves of exposure to HIV infections cannot be appropriately dealt with until, vigilance is placed upon some of the dangerous avenues where HIV/AIDS crept into the society one of which is the habit of scantily dressing. This is more pungent when considering the fact that most 'scantily dressers' have 
experienced sexual intercourse and that sexual overture begins with admiration of girl's appearance by the opposite sex.

Since educational attainment shows a significant negative impact on scanty dressing habit, it is recommended that governments and other stakeholders should continue intensifying more on compulsory education for all the giris from primary and up to the tertiary level. However, because the presence of these styles of dressing is not place-specific but cut across places like hotels/club houses, party, churches, universities/colleges, market places and offices; parents/guardians and other stakeholders should be obliged to protect and promote normal dressing habit through open rejection of scant dressing in all places coupled with consistent Dressing Habit Enlightenment Programmes (DHEP).

All schools and higher institutions should embrace dressing code ethic as being championed presently by few of the existing ones. Indulgence in scanty dressing could be curtailed by the provision of adequate information on sexuality and respect for Nigerian culture on appropriate dressing. In addition, it is no gain saying that the involvement of adolescent girls in scanty dressing habit portends greater danger for their sexual behaviour, their development and nation building in general. Proper upbringing with a sense of modesty in dressing would not only contribute to better quality of life but the ensuing better quality of life could enhance social and economic development of any country and her existence. A cultured and morally sound population could probably engender healthy productive population (labour), which if harnessed, would result in speedy economic advancement and realization of the targets of millennium development goals, especially in halting the prevalence of HIV among adolescent girls and reverse its spread. Finally, because of the position the adolescent occupies in the society, it is pertinent that in order for continuity of life to remain unbroken and for the elimination of the current laxity in sexual behaviour in the subSahara African region, the parents/guardians and other stakeholders should endeavour to repress all avenues for sexual misbehaviour that could aggravate the incidence of HIV/AIDS in the society. 


\section{REFERENCES}

Action Health Incorporated (2007). Success despite the Odds: Lessons on Early Marriage in Northern Nigeria. Action health Incorporated. 2007

Augustina, Situmorang (2003): Adolescent Reproductive Health in Indonesia. Consultancy Report Prepared for STARH Program, Johns Hopkins University, Center for Communication Program. Jakarta, Indonesia. September 2003

Caldwell, J. C (2000). Rethinking the African AIDS Epidemic. Population and Development Review. Volume 26 Issue 1, Pages $117-135$.

Caldwell, J. C and Caldwell, P., (1996). The African-Aids Epidemic. Scientific American, Vol. 274, No. 3, pp. 62-68.

Caldwell, J., Caldwell P. and Quiggins P (1989). The Social Context of AIDS in sub-Saharan Africa. Population and Development Review, Vol. 15, Issue 2 (Jun) 1989, 185-234.

Caroline H. Bledsoe and Barney Cohen (1993): Social Dynamics of Adolescent Fertility in Sub-Saharan Africa Appendix Difficulties in Analyzing Adolescent Fertility. National Academy of Sciences, 1993. "National Academy Press, Washington,

D.C.

http://www.nemstrojans.org/Download/Dress_Code.pdf

Faoye Grace and Lana Bolanle (1998): Facts of Life for Adolescents: a guide for teenagers and young adults on responsible and safe sexuality. 1998

Federal Ministry of Health (FMOH), (2002). National Reproductive Health Strategic Framework and Plan. Federal Ministry of Health Abuja June 2002.

Federal Ministry of Health (FMOH) (2005). Technical Report. National HIV/Syphilis Sero-Prevalence HIV Sentinel Survey. Department of Public Health, National AIDS/STI Control Programme. NASCP/FMOH, Abuja. Nigeria.

- Federal Ministry of Health (FMOH), (2007). National Strategic Framework on the Health and Development of Adolescents and Young People in Nigeria. Federal Ministry of Health Nigeria. July 2007. .

Hughes Ann and Grawoig Dennis (1971). Statistics: A Foundation for Analysis. Addison Wesley Publishing Company. 1971

Joint United Nations Programme on HIV/AIDS (UNAIDS) (2002). Report on the Global HIV/AIDS Epidemic 2000. Geneva: UNAIDS. 
Kuruvilla Laura (2007). A dying Virtue: Modesty in Dress from a woman perspective. August 19, 2007

Mangani Margaret (2005). Failing to distinguish between what is fashion and indecent dressing. Times Printpak Limited. ZAMNET Communication Systems Limited. Webservices, 2005

Marc J. Roberts, William Hsiao, Peter Berman and Michael R. Reich (2003): Getting Health Reform Right: a guide to improving Performance and equity. Oxford University Press, October 2003.

Matthews A. Ojo (2007: Religion and Sexuality: Individuality, Choice and Sexual Rights in Nigerian Christianity. Humanity Sexuality in Africa beyond Reproduction. Edited by Eleanor Maticka-Tyndale, Richmond Tiemoko and Paulina MakinwaAdebusoye. Action Health. Incorporated. Fanele Jacana Media (Pty) Ltd.

National Population Commission (NPC) and Federal Ministry of Health (FMOH), (2004): Population and the quality of life in Nigeria. NPC and FMOH. September, 2004

National Population Commission (NPC), (2010). 2006 Population and Housing Census of Federal Republic of Nigeria. Housing Characteristics and Amenities Priority Tables. Vol 2. National Population Commission. March, 2010

Odebiyi, A., and Vivekananda; F., (1991): AIDS in Third World Countries: Africa - What are the Alternatives? Scandinavian Journal of Development Alternatives, Vol. 10, No. 1/2, Pp.9199.

Odeleye, A. D. (2000): Psychological Correlates of Contemporary Clothing Behaviour of Nigerian Undergraduate Students. An Unpublished PhD. Thesis, Faculty of Education, Department of Foundations and Counseling, Obafemi Awolowo University, lle-Ife, Nigeria..

Ojo, Olugbenga David and Fasubaa, O. B. (2005): Adolescent. Sexuality and Family Life Education in South Western Nigeria: Responses from Focus Group Discussion. Journal of Social Sciences, 10(2): 111-118. Kamla-Raj 2005

Ojo, Olugbenga David and Odeleye Bidemi (2008): Contemporary Clothing Habits and Sexual Behaviour of Adolescents' in South Western Nigeria. Journal of Human Ecology, 23(1): 3944. Kamla-Raj 2008. 
Onwuamanam, Donatus, O. (1995): Sexual networking among youth in southwestern Nigeria. Health Transition Review. Supplement to Vol. 5, 1995, 57-66

Pemplenani Mufune (2003): Getting Health Reforms right. CODESRIA Bulletin, Special Issue 2, 3, \& 4, 2003 Page 44

Population Council and United Nations Population Fund (UNFPA) (2002): HIV/AIDS prevention guidance for reproductive health Professionals in Developing-Country Settings. Population Council Inc., UNFPA. 2002.

Population Reports (1995): Meeting the Needs of Young Adults. Series J (41) Family Planning Programs: 1-38.Rubistein, Ruth P. (1995): Dress Codes: Meanings and Messages in American Culture. Westview Press, Colorado U.S.A. 1995.

Sykes, Alan O. (1993): An Introduction to Regression Analysis, The Inaugural lecture. Chicago Working Paper in Law and Economics. 1993.

http://www.law.uchicago.edu/Lawecon/WkngPprs_0125/20.Sykes.Regression.pdf

Wardrobe Oxygen (2006): Dress for Respect. Wardrobe Oxygen. http:/ / www.wardrobeoxygen.com/2006/10/dress-forrespect.html

World Health Organisation (1989). The Reproductive Health of Adolescents: A strategy for action, A Joint WHO/UNFPA/UNICEF Statement, World Health Organization, Geneva, 1989.

World Health Organisation $(1999,2001)$. DEFINITIONS AND INDICATORS IN FAMILY PLANNING MATERNAL \& CHILD HEALTH AND REPRODUCTIVE HEALTH USED IN THE WHO REGIONAL OFFICE FOR EUROPE. Reproductive, Maternal and Child Health European Regional Office. World Health Organization Revised March 1999 \& January 2001 
